\title{
Smart Ancient Cities: Towards PAES Compilation. The Case History of Magliano-Tuscany Region and Canary Islands
}

\author{
Federico Giannuzzi ${ }^{1}$, Ezio Mesini ${ }^{1}$, Fedora Quattrocchi ${ }^{*}$ \\ ${ }^{1}$ Università di Bologna “Alma Mater Studiorum”, Bologna, Italy \\ ${ }^{2}$ INGV: Istituto Nazionale Geofisica e Vulcanologia, Via di Vigna Murata 605, Roma, Italy
}

Corresponding Author Email: fedora.quattrocchi@ingv.it

https://doi.org/10.18280/ti-ijes.632-450

Received: 11 March 2019

Accepted: 26 April 2019

\section{Keywords:}

PAES-PEC, smart cities and communities, smart ancient cities, energy density low carbon, Magliano (Tuscany region), Canary Islands

\begin{abstract}
The purpose of the paper is to analyze the state of the art of the Territorial Energetic Planning (Piano Energetico Comunale, PEC, including PAES - Piano Azioni Energia Sostenibile) keeping in mind the various available energy-heat production-technologies with particular reference to those "low carbon", that include the Renewable Energy Sources ones (RESs). The roles of the various corporate bodies are examined departing from the European Energetic Planning, passing for the National Energetic Strategy up to focus on a more specific situation for a specific country with the Plan of Action for the Sustainable Energy (PAES). Besides, evolving the European "Vision" of the classical "Smart Cities and Communities" are deepened the concept of "Smart City and Smart Ancient Cities", in the frame of new strategies for the sustainable mobility, the energetic retraining and the diffusion of the Renewable Energetic Sources (RESs) in reworked Ancient Towns, toward cultural heritage, architectonic restoration, anti-seismic strengthening in a unique resilience path for the single-out Ancient Town.

The first example of "Smart Ancient City" and "Low Carbon" ancient town, typical of the Italian's Panorama as select example of an ancient suburbs, is the Municipality of Magliano (Tuscany Region), that has a Convention of Research with INGV (National Institute of Geophysics and Volcanology), where an important energetic-architectural retraining has been analyzed for illumination, transports, schools, etc. of the Municipality, including the Bio-masses/Biomethane Plant locally and all the most recent evolutions developed by this Municipality.

Another example refers to a study realized in the Canary Islands, that thanks to their territorial characteristics and the geographical position on the sea, they can anticipate technologies from the European calls HORIZON 2020 "Smart Cities and Communities" with an evolution toward the "Smart Ancient Cities" concept, using RESs of last generation both in the eolic and in the photovoltaic framework.
\end{abstract}

\section{INTRODUCTION}

The most urgent problem of Humanity (very soon 8 billion people) is to produce a large quantity of energy by the minimum Green House Gases production (onward GHGs), in the minimum space and time as possible [1-5].

This work, that is a part of the HORIZON 2020 "Smart Cities and Communities" calls, is devoted to the examinate some energy technologies, including renewable ones and their possible applications in Italian territory [6-7] and also abroad. We started from typically Italian contexts, that is the ancient villages, with a tourism-vocation, near the sea, but perhaps slightly on a hill, where typically the ancient villages rose for medioeval defensive reasons, deepening from the concept of "Smart Cities and Communities" toward the concept of "Smart Ancient Cities". In doing this, new strategies were exploited on one hand for sustainable mobility, energetic retraining and diffusion of the Renewable Energetic Sources (RESs), and on the other in parallel with the "Unified European Directive for the use of subsurface and lands to produce energy/heat/resources". The establishment of European calls for proposals such as "Smart Cities and Communities"
HORIZON 2020, aim to create a European area of research and development, mobilizing private and public investments in some sectors considered decisive for the competitiveness such as energy and low-carbon transport, waste treatment and public clean water. To participate at European level in the aforementioned calls, there is a mandatory need to have a welldefined energy framework and planning, certificate already in official protocols, for each municipality beforehand; this is identified in the Sustainable Energy Action Plan (SEAP).

The SEAP is an energy planning document, associated with the individual and local administrative entity in its peculiarity, which outlines a data collection profile, energy production activities and performs basic surveys that lead to tangible, experimental measures evolved in the state of the art and really applicable energy policies. The SEAP must clearly indicate the strategic actions that the local authority intends to take to achieve the objectives set for 2020 (HORIZON 2020).

\section{METHODS}

As part of a Research Convention between INGV (Fedora 
Quattrocchi, Scientific Responsible) and the Municipality of Magliano (Tuscany Region), real energy values produced by public and private structures were taken into consideration, as an experimental basis for the data to be processed, bearing in mind that the concept of energy encompasses all possible sectors: corporate, private, public and environmental (i.e., energy and heat production, but normalized to the GHGs that are cut and avoided in the atmosphere for the analogue energy production "no low carbon"). At the same time, energy technologies were studied and developed in a similar situation, a Smart Ancient City near the sea as well as the Canary Islands, and then a comparison was made between the two sites.

Before doing this, the concepts of PAES and the analysis of the Low Carbon Producible Energy Density [8-10] were translated into "Energy Density Productive Low Carbon (DEPLC)", producible as [MWhe/hectar/year] and including the one that produces heat $\left[\mathrm{Mwh}_{\mathrm{t}} / \mathrm{hectar} / \mathrm{year}\right]$ namely, considering the space-time variables too, often underevaluated or "hidden", not only for small and medium-sized enterprises, but also for small towns and ancient villages, with high cultural value and artistic.

The present study refers to data and consumption, coming from various technologies for energy production, which instead of being presented with different physical quantities were normalized to the DEPLC, with the relative $\mathrm{CO}_{2}$ emissions reduced and therefore avoided in the atmosphere, to be calculated instant by instant in the municipal ICT synoptic system. In summary, the work was structured as follows:

(1) the work of the last years of the Set Plan Energy is studied and reworked, then defining the National Energy Strategy (SEN) and prospects reach.

(2) the PAES (in Italian) or SEAP (in English) is critically studied and reworked and the general techniques to be undertaken and the research to be carried out are outlined in order to produce a technical draft for the single Municipality.

(3) a definition is made of the Municipal Energy Plan (PEC) and of the objectives set in the Action Plan for the single municipality.

(4) one enters more specifically with regard to the interventions and concrete possibilities that can be implemented in the territory of a small municipality like that of Magliano, identifying the various operational chains; starting from this experience, the Italian potentials referring to the new concept of "Smart Ancient Cities" have been highlighted, that is to say ancient tourist towns with a growing need and potential for technological, energy and historicalarchitectural restoration, taking the advantage of Herity International partner in writing EU Projects (www.herityinternational.org) to make them live the rest of the year and not just in summer.

The main objectives concern low-carbon energy productivity and the increase in energy efficiency [11] buildings, municipal infrastructures, large, small and mediumsized industrial plants and public transport, as well as the diffusion of hybrid plants that can help stabilize the network, in parallel with the classic RESs development by simply improving the input data for irradiation, wind speed and heat [11-14]. Here is an analysis of two different views taken into consideration and the methods used.

\subsection{Smart ancient city Magliano (Tuscany Region)}

Given that there are few studies of municipal territorial energy planning in Italy, with particular reference to the synergies and uses of the soil and subsoil (energy storage, gas, $\mathrm{CO}_{2}$ or nuclear waste, geothermal energy, RESs) and considering that these studies and assessments of the territory, carried out by research institutions, encouraging international schools on the topic too $[8-10,15-16]$ together with Italian universities; in this manner all together we are increasingly in demand for the drafting of European proposals, the degree thesis projects are part of a Research Convention between INGV and the Municipality of Magliano, for the formulation of the SEAP, that in turn addresses the PEC (Figure 1 and Figure 2).
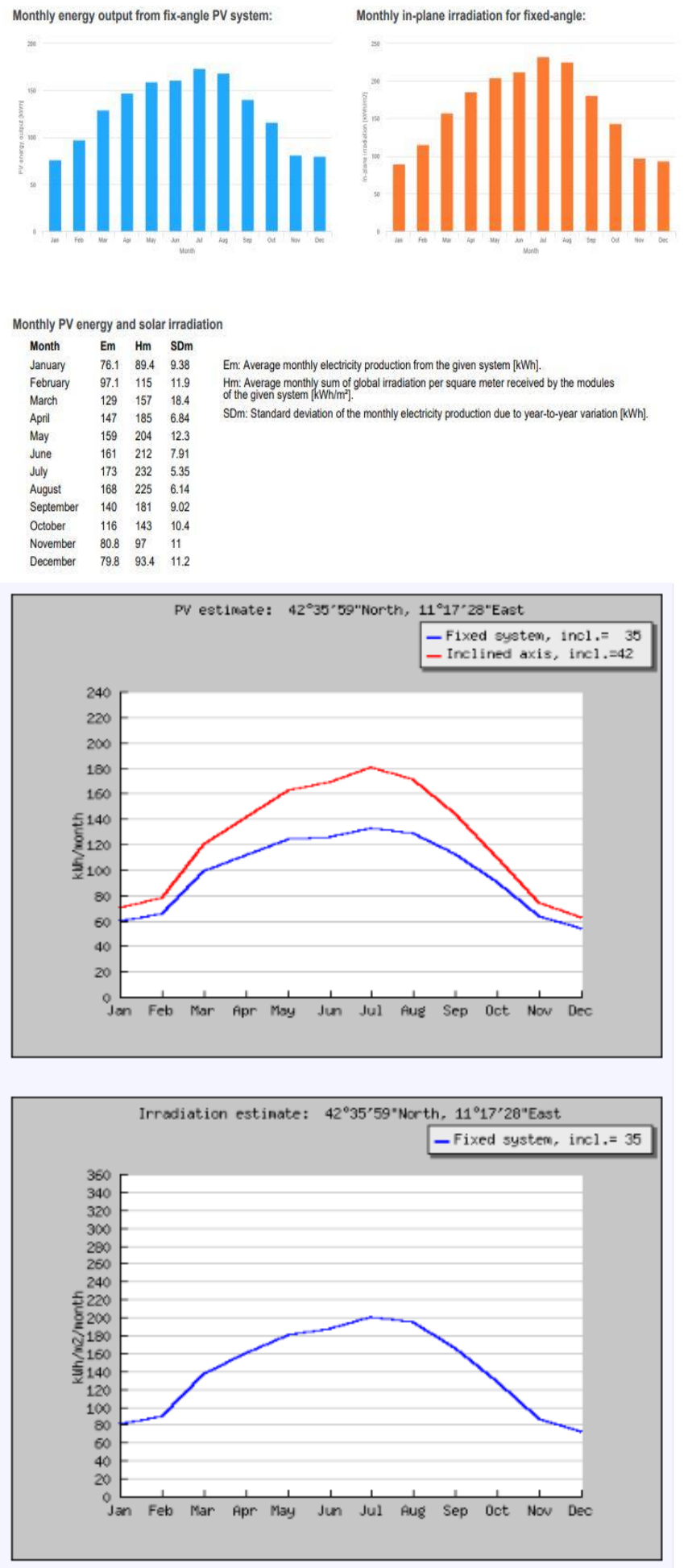

Figure 1. Solar irradiation used for the calculation of potential energy production in Magliano 

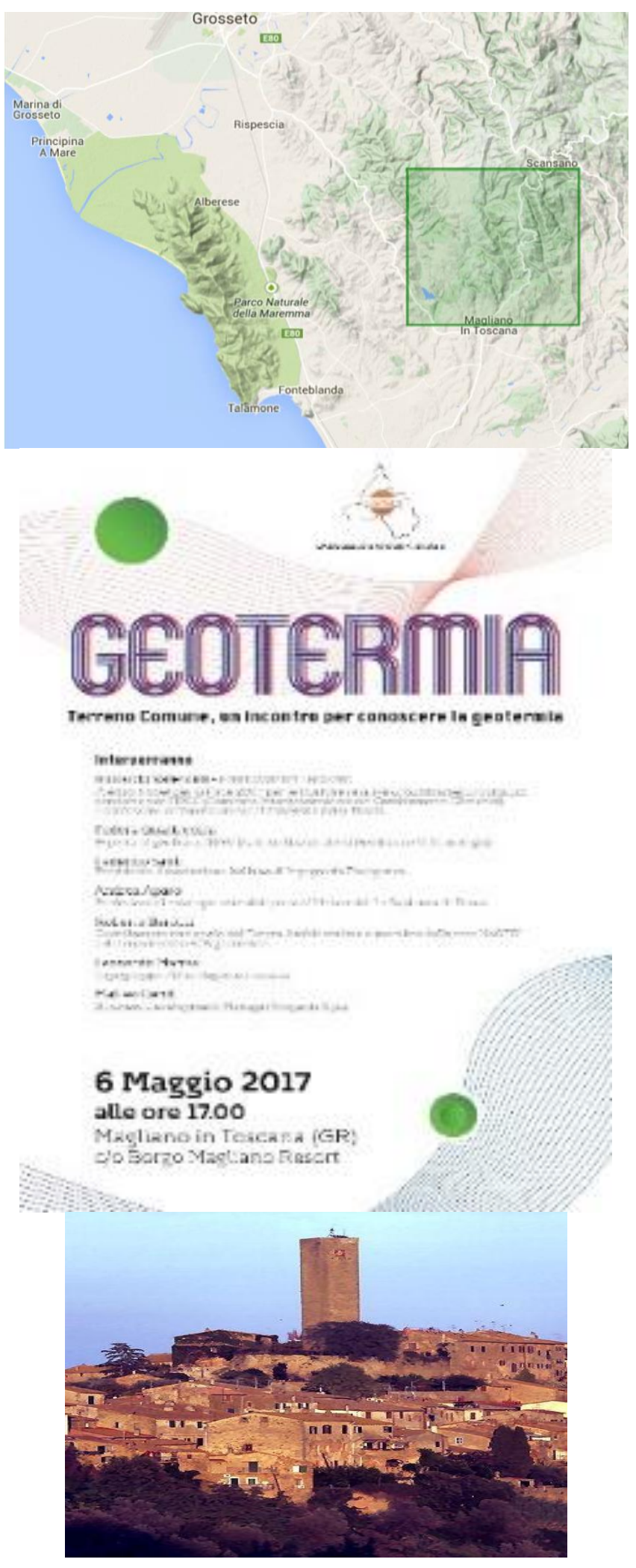

Figure 2. A picture of Magliano where is possible to see what kind of structures exist to improve the RESs and photovoltaic paints or mini-wind flags devices, and the

Pareda Geothermal Permit area, about which a Conference was done in 2017

The research is based on a study of the energy density calculation [Mwh $/$ hectar/year] including the one that produces heat $\left[\mathrm{Mwh}_{\mathrm{t}} /\right.$ hectar/year], [8-10] can be produced with low-carbon technologies, energy efficiency and energy savings, in time and space, for the Municipality of Magliano, for the purposes of territorial energy planning, of lands and subsurface, together with an energy rehabilitation parallel and superimposed on the artistic-archaeological-cultural and touristic "restructuring", to attract young technologists/engineers as well as handicraft, in search of lowcarbon work/job and sustainable tourism, in turn generating new human activities, in a reproducible synergy for all the countless ancient Italian villages. The same model of work is reproducible along the ancient roads of Asia and Africa where to bring back the African-Middle East migrants to their families, but far from the giant African-Asian cities, where people become alienated, giving value to the ancient cities on the "caravan routes" in the southern continents.

The aforementioned collaborative and study sharing approach between INGV and the Municipality of Magliano and an energy-environmental and business engineering university department represent its basic and partial data set hinges. The area of study of the municipality is characterized by potentials of energy density both electrical and thermal $\left[\mathrm{MWh}_{\mathrm{e}} / \mathrm{hectar}_{\text {year }}\right.$ and $\left[\mathrm{Mwh}_{\mathrm{t}} /\right.$ hectar/year] of use of RESs, energy storage, biomass sources and energy efficiency developments (including low or medium enthalpy geothermal energy [13-14] in order to provide a precise and detailed energy picture in evolution, a visible by citizens by an ICT summary panel in the main square of the city, calculating the MWh produced, that consumed and the emitted GHGs, as avoided in the atmosphere with respect to the ancient no-low carbon technologies. The new studies and calculations add to the calculation of the potential of electrical and thermal energy density $\left[\mathrm{MWh}_{\mathrm{e}} /\right.$ hectar/year] and $\left[\mathrm{Mwh}_{\mathrm{t}} /\right.$ hectar/year] in the already studied Italian regions, however they should be developed in greater detail in the single municipalities as they require the "Smart Cities and Communities" calls, duly modified towards the "Smart Ancient Cities" in the European calls for HORIZON 2020.

The various operational and potentially operational energy supply chains have been classified for the Municipality in question by 2025, but we premise that the environmental and energy assessments are reported in terms of actually produced quantities and those that can be produced later for an intervention aimed at improving the low-carbon energy production of the municipality and we will report everything

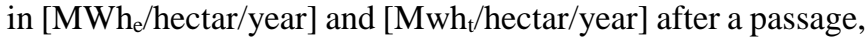
for the municipal buildings considered, in units of measurement of $\left[\mathrm{kWh} / \mathrm{m}^{2 *}\right.$ year $]$ or according to the consumption data provided by the municipality. The current situation is illustrated, and, subsequently to actions to increase energy efficiency and the addition of RESs, low-enthalpy geothermal energy [14] and more, future prospects with associated improvements and energy savings.

The objective of the study of the chain of buildings, infrastructures and installations is to carry out an energy analysis of them as found in the territory of the municipality; from these, a unitary "energy producibility" or "energy density" variables are extrapolated (Penu=electric and thermal $\mathrm{kWh} /$ $\mathrm{m}^{2 *}$ year), which are our benchmark for energy requalification and efficiency improvement of the structures, or for an energy improvement and a reduction of $\mathrm{CO}_{2}$ emissions in the municipality of Magliano. A second parameter for the analysis is the "unit energy cost" (Cenu=euro/kWh) expected compared to the real one paid in recent years (experimental data of the Municipality of Magliano). The thermal and electrical analysis was differentiated according to the operating sectors. For the sector the municipal buildings and schools RESs have been 
analyzed, in particular, focusing on photovoltaic and solar thermal. We refer to small plants that include the whole generation with an installed power lower than $30 \mathrm{~kW}$.

The new technologies are then analyzed one by one, verifying the possibility of their implementation to the Municipality of Magliano.

From the data provided by the Municipality and which have been subjected to analytical and critical review (compilation work), it appears that in the last year the elimination of obsolete thermal machinery took place, replaced by highperformance heat pumps. Through energy efficiency actions we want to make all the public facilities belonging to the Municipality and schools self-sufficient.

The average annual production in $[\mathrm{kWh} / \mathrm{kWp}]$ is quite optimal and, after an energy efficiency intervention, the small municipal needs have been met. Recently, low-consumption heat pumps (Hitachi) have been introduced to the municipality, used for the heating of the premises and for the production of ACS (Acqua Calda Sanitaria, in English DHW) in the municipal building, however the efficiency actions should continue and precisely: by inserting solar thermal or photovoltaic on the roofs of municipal buildings such as library, town hall and schools. In fact, with the solar thermal, it would meet the needs of ACS (DHW) production for the building and if it were not available due to any failure, lowconsumption heat pumps would come into operation, which in turn could be energetically powered with photovoltaics, making the system is completely autonomous and renewable. An evaluation of the potential energy production, including the mini-wing flags devices on the castle and walls, was performed partially as a function of the permits released by the "Sovra-Intendenza alle Belle Arti". The Vision of the "Rigenerated Ancient Walls and Castles to produce Energy" would consist in the development of the applications of "graphene" and of nanotechnologies for the production and storage of electric energy in contexts of particular landscape and ancient edifices of historical interest, where it is necessary to minimize the impact on the landscape-architecture, extremely relevant. The graphene film, applied to historical walls, as well as to serve to produce energy, could also constitute an invisible but very effective barrier to the infiltration of meteoric water. Water, in fact, percolating inside the historic walls removes the mortar (binder), weakens its structure and relatively quickly causes very serious damage, which can also cause it to collapse; precisely on this issue a problem that has had to be faced recently concerns the collapses of some parts of these historic walls, therefore the idea of operating on them, would initially focus on a restructuring, to then conduct an energy requalification Moreover, this graphene film could mask the structural "anchors" the enhance strength to the ancient walls, but that could be hidden by photovoltaic devices on. Another application considered therefore is the "photovoltaic" paint, which is very well applicable, for example, on some historic walls of an ancient village, as they are invisible and without particular environmental impact, capable of capturing the sun's rays and transforming them into energy, to satisfy small needs. An excell table was produced, which can be used directly in the future for all ancient villages, simply by varying the walls perimeter length and height of the walls as well as articulating an ArchGIS of the masonry, to be "energized" and protected, with photovoltaic paints.

Furthermore, it was verified whether a certain perimeter of pavement construction could be carried out with a very low environmental and landscape impact - albeit an energy producer - we refer to the technology of piezometric tiles, which trampling them, in a certain area of intense passage of people (commercial high-frequentation pathways, etc...) produce low-carbon energy. The cost of these energyenvironmental applications, currently unthinkable because it is still without a market and without real incentives, could decrease in short time intervals and have a virtually zero impact on the landscape, as well as being fun for schools and "environmental events". This solution could therefore be applied in an undifferentiated manner throughout the municipal area (local roads, trekking paths, river-banks, etc.).

Some data on public lighting in the Municipality of Magliano were analyzed, with the aim of further improving low-carbon electrical energy production and reducing oxidised $\mathrm{CO}_{2}$ emissions.

From the data provided by the Municipality of Magliano, it is possible to summarize individual and total power and quantity of all the light points, in the primordial phase, i.e, before the intervention and after the replacement of the lamps with LED technology. After the redevelopment of the bodies belonging to public lighting, an average annual saving of 97 tonns of $\mathrm{CO}_{2}$ was calculated.

Energy Diagnosis of buildings in the Municipality of Magliano Toscana was carried out, in particular of two school buildings, namely: kindergarten and elementary school and middle school.

Finally, the investments required in the next imminent years (energy planning) to make energy structures efficient were assessed, with a relative reduction in atmospheric GHGs emissions and an increase in renewable energy applied to annual energy production, with the replacement of obsolete machinery and systems.

It is important to remember that the municipal building par excellence is an existing building and that the energy performance must be compared with similar existing buildings, as for public buildings built starting from 2018 the reference value is that of NZEB (Nearly Zero Energy Building), or almost zero energy buildings.

The work overview the future need of the Luigi Vivarelli Biomass-Biomethane energy production Plant (more than 100 MW), planning to write a specific EU project mostly for the optimization of the bio-methane path along the plant, and associated software, and further thesis degree should be dedicated.

The issue of medium-enthalpy geothermal energy in the Magliano Municipality, to produce energy is still under discussion to the Authorities: after the stop to the permits to perform deep drilling in 2015 , for private companies, the binary-cycle medium-enthalpy geothermal energy in Tuscany still represent a fair, as a consequence of the "speculation" and no-ethical behavior of certain little companies, among them born in Fiscal Paradises of Europe.

\subsection{Canary Islands: 100 \% renewable "EI Hierro"}

The Canary Islands are an archipelago composed of 9 islands, 7 large and 2 smaller. They are located off the northwest African coast, they are all of volcanic origin. Given their strategic position and their structural conformation, they are suitable for the installation of technologies that produce energy from the various renewable RESs, such as the heat present under the earth's surface but in particular the wind, the sun (the sea-wave motion could also be exploited). El Hierro, 
the smallest Island in the Canary Islands, which covers about 250 square kilometers, has become, for some years, a point of reference for all those places in the world that intend to feed their activities exclusively with clean energy. The geographical conformation of the Island is very varied, given that it passes from the top of Malpaso $(1500 \mathrm{~m}$, therefore a greater height than the hill of Magliano that does not exceed the $400 \mathrm{~m}$ of height) up to $300 \mathrm{~m}$ of depth below the level of sea of the marine reserve of La Restinga; this landscape has been used for the construction of a hybrid hydro-wind system that can satisfy the energy needs of the population, avoiding the emission of approximately 18700 tons of $\mathrm{CO}_{2}$ and the use of 40,000 barrels of oil for the diesel plant. The wind farm consists of 5 blades of $1.2 \mathrm{MW}$ each and its production remains almost constant throughout the year [Mwhe/hectar/year of approximately 1500 hours]. The artificial lake, located a short distance away, acts as a hydraulic deposit and thanks to the energy it can receive from the wind turbine blades it acts as a pumping station, which brings water back to the upper basin, and which is useful for balancing the electricity grid in the moment of lack of wind sources. In addition, there is also a diesel power plant for emergencies that was the old power source to meet the needs.

\section{DISCUSSION MERGING PRE-EXISTING AND NEW RESULTS}

The results obtained in the various elaborations, obtained also thanks to the collaboration with Italian and Spanish municipal administrations (with particular reference to Magliano) and technical office, which have cooperated in order to provide access to the data and information in their possession, are exhibited.

The experience in the technical field acquired during the experimental phase at the Renovables Nueva Era and Kemical Ecological Canaria companies, both operating in the Spanish territory of Gran Canaria, dedicated to the production of energy from renewable sources (RESs) which allowed to implement the methods and technological applications illustrated above. Comparisons have been made in broad lines between the two different national systems (Italy, Spain) and in general at European level, highlighting the enormous potential to render alive these Smart Ancient Cities located among the sea and a medioeval-defense hill near the sea, as Magliano is: these ancient cities are lived only in the summer, while by this new energy-winter tourism implementation the city will be lived in all seasons.

Table 1. Calculation of thermal consumption and relative breakdown by single type of service

\begin{tabular}{|c|c|c|c|c|c|c|c|c|c|c|c|c|c|}
\hline \multicolumn{14}{|c|}{ RISCALAMENTO - Consumi mensili } \\
\hline Trpologia & Gen & feb & Mar & Apr & Mag & Giu & Lug & $\mathrm{AgO}$ & Set & Ott & Nov & Dic & \begin{tabular}{|l|l} 
Totale \\
\end{tabular} \\
\hline $\begin{array}{c}\text { Consumi } \\
\text { elettricic caldaia } \\
{[\mathrm{WWh}]}\end{array}$ & 13.880 & 39.800 & 16.381 & 4.390 & . & . & . & . & - & . & 10.275 & 14.861 & 99.586 \\
\hline $\begin{array}{l}\text { Carburante } \\
\left(\mathrm{Sm}^{3} \mathrm{~d} \mid \mathrm{G} P \mathrm{~L}\right)\end{array}$ & 581 & 1.665 & 685 & 184 & . & . & . & * & . & 430 & 430 & 622 & 5.494 \\
\hline
\end{tabular}

Finally, an evolutionary Vision of the situation is provided, with the aim of raising awareness among the users of municipal services towards good low carbon energy practices to be carried out, finding the main solutions in reducing consumption and greenhouse gas emissions, in the increase of renewable energy production, in accordance with the European objectives set for HORIZON 2020 and for the SET PLAN ENERGY.

The results obtained refer to the two examples previously analyzed, in the case of the Primary Schools of Magliano, which results in the energy class E category, the following energy reference indicator (EPI) was identified: $\left[\mathrm{kWh} / \mathrm{m}^{2} /\right.$ year $]$. It represents the recorded energy consumption values (electricity and heat demand) in relation to the surface unit per unit of time (Table 1). Only with the same variable unit is possible to compare the studies on this topic.

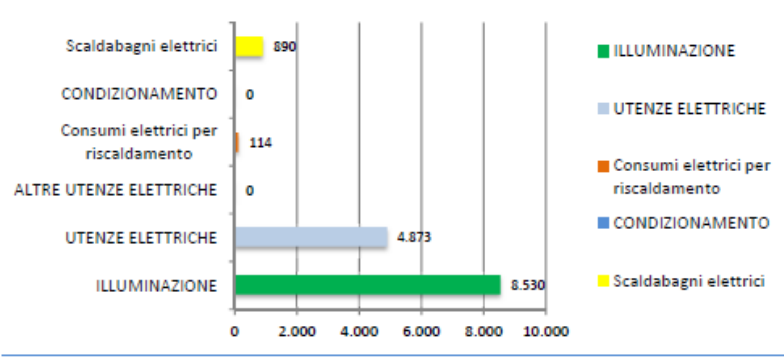

Figure 3. Analytical reworking and summary of the electrical consumption in Magliano in [KWh/year]

The electricity consumption and the thermal consumption were analytically reconstructed to highlight the distribution of the same according to the type of services. The electrical energy consumptions associated with the General Services are mainly due to the lighting of the structure and to the other electric utilities present in the classrooms and in the refectory (PCs, printers, servers, etc.), among which there is the presence of electric boilers used for the production of ACS (Figure 3). In relation to thermal consumption, they are solely attributable to the heating of the structure. The electrical consumptions recorded in order to satisfy the request are to be charged mainly to the lighting, to the motive power for the electric utilities, for the operation of the water heaters.

The thermal consumption is to be attributed exclusively to the heating of the school building (winter air conditioning) and therefore attributable to the General Services. Since there are no other thermal uses, $100 \%$ of the heating LPG is attributable to the winter air conditioning process.

Since electricity consumption and thermal consumption are all attributable to general services, the identified indicator compares energy consumption to the area unit (consumption as $\left[\mathrm{kWh} / \mathrm{m}^{2}\right]$ ). The benchmark of the indicators is therefore similar to the one that can be considered for buildings with similar energy demand values, expressed in $\left[\mathrm{kWh} / \mathrm{m}^{2} *\right.$ year], as defined by the Energy Performance Certificate (APE).

First intervention: The proposal of energy efficiency provides for the replacement of the current lighting fixtures with new LED lighting fixtures, under the same conditions of use (the use of lighting has not been normalised because it does not depend on seasonal factors). The replacement of the current neon lighting fixtures with a power of $36 \mathrm{~W}$ is hypothesized with LED lamps with a power of $18 \mathrm{~W}$. From a technical view it has been hypothesized to replace exclusively the neon tubes with LED tubes, maintaining the current ceiling lights. The cost considered includes the supply of the new lamps and their installation as well as the disposal of the previous lamps to Neon. The discount rate was set at $5 \%$ and the financial calculations were carried out net of any form of incentive, including taxis and with a reference period of 20 
years.

Furthermore, the verification of the insertion of brand new ECOTECH GLASS lamps, of exquisitely Italian production, is underway: these are new led glass panels (panel lights) with entirely glass surface and without edges (therefore without abusing the typically Asian metal profiles, also considering the scarcity of the first material), including the ECOTECH BIOVITAE panels that with a technologically revolutionary solution allow to reduce the bacterial load and are therefore ideal for a hospital or in special healthcare / chemical environments (white rooms, ICT rooms etc...). BIOVITAE lamps as a Class I medical device that can be installed in panels of different sizes customized on already existing infrastructures because they can be made to measure. The light emission occurs at certain frequencies, safely preventing outbreaks of infectious diseases, acting on certain molecules the porphyrins - which make the microorganisms / allergens share particularly sensitive to a certain type of light, in its photo-catalitic function) for all of Grosseto City.

Therefore energy efficiency improvement inside the PAES document, also depends on the choice of materials: in this case (IP65 glass), i) reduced thickness; ii) resistance to abrasion with protection up to 200 times higher than normal plexiglass; iii) scratch and abrasion resistance over time and high stability over time; iv) reduced light absorption; $v$ ) efficient heat dissipation, from the geometry of the layers of the chosen material and the diffusers with very high transparency and energy efficiency (increased by $90 \%$ compared to the classic illuminators in the workplace); vi) high antistatic protection capable of dissipating up to 1000 times the amount of static electricity of normal plexiglass; minimization of cleaning; usability in any environment.

Second intervention: The second solution to improve efficiency is represented by the replacement of the old boiler with a condensation combined with the installation of thermostatic valves on the radiators. The current management of the delivery temperature which can be modulated as a function of the external temperature, combined with the thermostatic valves, would make it possible to optimize the operating temperature of the supply water and to have a return water temperature conducive to condensation, while maintaining the current radiators. The discount rate was set at $5 \%$ and the financial calculations were made net of any form of incentive, including VAT (which represents a cost for the public body in question) taking into consideration a reference period equal to 20 years.

Third intervention: analyzed for the three buildings: nursery and primary school, middle school and municipal building.

Using photovoltaic software, the production values obtained were calculated by entering the data, needs and climate zone of the Municipality of Magliano and for the individual buildings that we will analyze. All measurements are in $\left[\mathrm{kWh} / \mathrm{m}^{2 *}\right.$ year $]$ and an example is given for a building in Magliano.

Further design analyzes were carried out with the collaboration of foreign companies: RENOVABLES NUEVA ERA and KEC MEDIO-AMBIENTE, which deal with renewable technologies such as the production of energy from photovoltaic panels, at family level with medium-small installations, but above all at hotel sea district level, reaching medium-large size systems that can meet the energy and water requirements required in a renewable manner. At the same time, it treats the production of Domestic Hot Water (ACS,
DHW) using solar thermal technology; air-conditioning of buildings, air-conditioning of private or hotel swimming-pool complexes, use of heat pumps, air-to-air or high-temperature air-water machines.

As part of the activity carried out in the company, an engineering analysis was done of the various technologies with which to compensate for an excessive production demand. Concretely, the work was to physically go to the workplace by analyzing installations that had already been completed and others under construction, however installation projects were also carried out with subsequent start-up and maintenance operations on systems that had already been in operation for years. One of these analyses concerned the Roca Negra Hotel in Agaete, a structure that is being extended, with an ACS production system using heat pumps supported by a high temperature machine with a $\mathrm{COP}=7$, all integrated with renewable energy coming from solar source, or with solar thermal panels on the roof of the building. In addition to an analysis of the elements that make up the installation there is the economic part of the investments and the creation of estimates. Another project is the one on the Serenity Hotel, for the air conditioning of the pool, for the production of DHW and to meet the energy needs of the same structure, thus making it energy efficient and sustainable. For the design, the Solidworks ${ }^{\mathrm{TM}}$ or Sketchup ${ }^{\mathrm{TM}}$ software is used, which refers to the BIM methodology to provide a clear and precise 3D idea of the project in general. We are talking about a hotel with 40 rooms, so with an average of $80-100$ people inside; the average diary consumption of a person is fixed at 55 liters/person which for legislation must be provided at a temperature of $60{ }^{\circ} \mathrm{C}$, due to a legislative issue arising from the danger of legionella, a bacterium that proliferates at temperatures 35$45{ }^{\circ} \mathrm{C}$. There are two swimming pools, one for adults and one for children. The installation thus calculated must consist of 45 solar thermal collectors, of which 24 are used for the production of DHW and 21 to air-condition the pool, of which we consider there is a loss of $2.5^{\circ} \mathrm{C}$ per day. The model of the collector to be used is the PA-E model each with an area of $2.17 \mathrm{~m}^{2}$, which analyzed according to the territory on which it is installed will give a certain amount of $\left[\mathrm{W} / \mathrm{m}^{2}\right]$ precisely in this case we must consider $700\left[\mathrm{~W} / \mathrm{m}^{2}\right]$.

In recent years, there has been a strong one-to-one correspondence between the city environment and Information and Communication Technology (ICT), which is a necessary condition for facing the challenges of sustainable development in a smart way at the local level. The theme of the Smart City is today pervasive and dominant compared to any other traditional urban theme. It represents a strategic priority of HORIZON 2020 and the different European regions borrow local guidelines on research and innovation. Sustainability should not be understood as a simple superposition of a technological code to the architectural project in a pure cladding perspective, the sustainable project is a set of good practices or architectural and urban composition rules, accompanied by the use of technology or the latest electronic discoveries supporting the complex urban functional mechanics.

In summary, a city or an "Ancient City" on an hill near the sea, as those analyzed, could be defined as "Smart" when investments in human and social capital, in traditional infrastructures, in mobility, in energy efficiency, in environmental sustainability, fuel sustainable economic development and a high quality of life, with a wise management of natural resources, through a method of 
participatory governance, which includes citizens in the definition and implementation of an integrated system of sustainable urban policies. Environmental management and monitoring is very important, as the understanding of its impact leads to an increase in regulation and activities aimed at reducing pollution. In this context we want to emphasize the new concept of "Smart Ancient City" and Magliano in Toscana is just one example, to highlight the importance of ancient villages and the desire to re-evaluate them, not only artistically and culturally but also from an energy point of view ,with a restructuring and "smart" devices enhancement, that can make them appreciable also at European level as resources and artistic-energetic heritage (Herity International as partner in the project for the future development). So, we want to concentrate primarily on small cities and countries that have ideal characteristics and dimensions to implement a revolution that will come to invest the big cities, after obtaining the knowledge and developing the means for a radical change. The ancient city as well as being the most fascinating, can also become the most sustainable and the most intelligent: it has extracted everything it needed from the place. The technologies in use borrowed from local materials $(\mathrm{km}-$ Zero concept) and the shapes followed specific functional needs.

Promotion of sustainable lifestyles, support for local agriculture and trade in "km-Zero concept" products, green purchases, adherence to the Covenant of Mayors, compilation of a detailed and complete SEAP of individual cities and countries, sustainable architecture, dissemination of electric mobility and infrastructure for vehicle recharging, these are only a few possible ways towards the common goal of energy efficiency and not just of our society

\section{CONCLUSIONS AND FUTURE PERSPECTIVE}

The paper integrates new data with the existing one and literature concerning the new energy technologies applicable to Smart Cities and Communities and here defining and emphasizing the concept of Smart Ancient Cities and their use. Some practical examples are reported, aimed at encouraging efficiency energy, devices adaptable to walls and castles, including the mini-wing flags devices, the reduction of energy consumption and Green House Gases (GHGs). In addition, RESs were implemented (low-enthalpy geothermal energy, the Biomass/Biomethane Plant). It is exemplary, the Luigi Vivarelli's Plant in Magliano, is exemplary, not treated here only for a question of available space, which can be imitated throughout the Country, of which and a critical historical analysis is underway, that considers also the future implementations to be made, both in ICT and in infrastructures.

These "low carbon" energy production technologies, however, appear to be a key tool at domestic, European and global level to achieve the objectives of safeguarding the environment, jointed to the CCS powerful technologies to cut the GHGs (www.globalccsinstitue.org). The electricity production measurements were normalized with the variable Producible Low Carbon Energy Density (DEPLC) expressed both in [MWhe/hectar/year] and in [MWht/hectar/year] as potentials of energy density respectively electrical and thermical. It has been analyzed and explained how the applications of energy redevelopment interventions in an ancient masonry village, such as Magliano, where, moreover, anti-seismic structural redevelopment can be coupled with energy redevelopment, can represent a driving force for architectural, tourist and economic development, especially when, as in the case of Italy, primary energy resources are not present in sufficient quantities. An excellent starting point was identified in drafting documents such as the SEAP (critically summarily revised in this work with the results of many small municipalities analyzed) and the PEC, with the aim of providing a Vision of the Energy Action Plan that we want to follow to achieve the European targets set for 2020 and later for 2030.

The study of the Municipality of Magliano was examined as a reproducible example that considers also the starting difference of the experimental data typical of a small municipality on which energy balances were carried. The balances were characterized by the integration of various technologies, including the typical photovoltaic one, to improve the energy production and efficiency of some public facilities. Moreover, the energy balances taken into account the limits and the improvements that can derive from the zeroemission transport, the ICT, the increase in RESs, the biomass / biomethane plant, the possible implementation of geothermal energy, and the awareness of the individuals that can promote a radical change, thanks to the incentive tools offered by local and regional governments.

Also the territory of Gran Canaria has some very interesting potentials, being characterized by consistent values of irradiance and a high wind resource, guaranteed by the intensity and constancy of the winds that lap the islands. In particular, on the island of El Hierro, excellent results have been achieved, guaranteeing the energy needs of the population in a $100 \%$ renewable way.

In conclusion, it is necessary, with a view to improving the distribution and methods of energy production, to know exactly the profile of the energy consumption of the cases in question, to make assessments regarding the local industrial plants, calculating in terms of normalization to the variable DEPLC in $\left[\mathrm{MWh}_{\mathrm{e}} /\right.$ hectar/year] and the specific activities carried out / planned. A detailed diagnosis of the municipal energy requirement allows the client to verify the presence and the technical-economic feasibility of interventions that reduce energy consumption for the same energy produced in the space and time unit (DEPLC). It would be important to support the PAES with accurate technical-energy surveys that provide reliability in the acquisition of real data, traceability on the origin of energy and consumption, verifiability on proposed interventions to arrive at a correct rationalization of energy flows.

The transition to an economy with greater efficiency and sustainability in terms of energy and environment, should increase the spread of innovative technological solutions, improve the competitiveness of the industry and security of supply (adopting zero $\mathrm{km}$ production situations), reduce greenhouse gas emissions and primary energy consumption in the European Union; all reviving sustainable tourism, economic growth with the consequent creation of high quality of life jobs in various sectors.

\section{ACKNOWLEDGMENTS}

F. Quattrocchi thanks a lot Prof. Enzo Boschi to discuss daily the concepts expressed in this paper. Many thanks to the Magliano Municipality Technical Office and the Major. Moreover, thanks to Set Plan Energy Enlarged Board, 
Ministry MIUR for the ideas and discussion at this table for many years. In addition, thanks for the external collaboration had in the past with Valentina Infante and Anna Buono (Matera Municipality) and with Cristina Del Prete.

\section{REFERENCES}

[1] (2009). EEA, EMEP/EEA air pollutant emission inventory guidebook. EEA, Copenhagen.

[2] (2012). EU Strategic Energy Technology Plan WTO workshop on environmental technology dissemination November.

[3] ICLEI. (2009). International Local Government GHG Emissions Analysis Protocol.

[4] (2006). IPCC Guidelines for National Greenhouse Gas Inventories.

[5] Chomkhamsri K, Wolf MA, Pant R. (2011). International reference life cycle data system (ILCD) handbook: Review schemes for life cycle assessment. Towards Life Cycle Sustainability

[6] Monforti F, Huld T, Bodis K, Vitali L, D'Isidoro M, Lacal-Arantegui R. (2017). Assessing complementarity of wind and solar resources for energy production in Italy. A Monte Carlo approach. Renewable Energy 63: 576586. https://doi.org/10.1016/j.renene.2013.10.028

[7] (2016). Patto dei Sindaci-per il clima e l'energia Commitment Document.

[8] Quattrocchi F, Boschi E, Spena A, Buttinelli M, Cantucci B, Procesi M. (2013). Synergic and conflicting issues in planning underground use to produce energy in densely populated countries, as Italy. Subtitle: geological storage of $\mathrm{CO}_{2}$, natural gas, geothermics and nuclear waste disposal. Applied Energy 101: 393-412. https://doi.org/10.1016/j.apenergy.2012.04.028

[9] Procesi M, Cantucci B, Buttinelli M, Armezzani G, Quattrocchi F, Boschi E. (2013). Strategic use of the underground in an energy mix plan: Synergies among $\mathrm{CO}_{2}, \mathrm{CH}_{4}$ geological storage and geothermal energy. Latium Region case study (Central Italy). Applied Energy 110: 104-131. https://doi.org/10.1016/j.apenergy.2013.03.071

[10] Buttinelli M, Procesi M, Cantucci B, Quattrocchi F. (2011). The geo-database of caprock quality and deep saline aquifers distribution for geological storage of $\mathrm{CO}_{2}$ in Italy. Energy 36(5): 2968-2983. https://doi.org/10.1016/j.energy.2011.02.041

[11] Bonanomi M, De Lumeri C, Lavagna M. (2012). Edifici a Consumo Energetico Zero.

[12] REPORT ISPRA. (2017). A methodology for optimization of the complementarity between smallhydropower plants and solar PV systems with the contribution of Ioannis Kougias, Sandor Szabo, Fabio Monforti-Ferrario, Thomas Huld, Katalin Bodis European Commission, Joint Research Centre, Institute for Energy \& Transport, Renewables \& Energy Efficiency Unit, IPR45, 21027, Ispra, Italy.

[13] Miller FP, Vandome AF, McBrewster J. (2010). Geothermal Energy Association (GEA).

[14] McGrail BP. (2010). Low-temperature geothermal power: A welcome neighbor in densely populated region? 34-th Course of the International School of Geophysics "Densely populated settings: The challenge of siting geological facilities for deep geothermics, $\mathrm{CO}_{2}$ and natural gas storage, and radioactive waste disposalUnderground coexistence and synergies for a sound energy mix in the post-Kyoto era, Erice. 